\title{
STATIC AND DYNAMIC ANALYSIS OF LINEAR SWITCHED RELUCTANCE MACHINE
}

This paper deals with the static and dynamic analysis of the Linear Switched Reluctance Machine (LSRM). The static parameters are investigated by means of Finite Element Method (FEM) for real LSRM and also for its optimized construction topology, where the air gap and mover dimensions are changed. The calculated static parameters are inputs into dynamic mathematical model of the LSRM. This model is simulated under Matlab/Simulink. The output values of the simulation are phase currents, voltages, flux linkages and total force in air gap of real and also optimized LSRM. The results comparison of the real and optimized LSRM is given.

\section{Introduction}

An optimization of electrical machines design is a topical task from the point of view of input electrical energy consumption (motoring mode) and production of electrical energy (generating mode) [1]. The main aim of the optimization is to increase efficiency of electrical machines and to decrease losses. The efficiency optimization of electrical machines can be carried out during their design. There are several methods for the design process, mainly the analytical calculation [2], [3]. A very useful tool for the design of electrical machines is Finite Element Method (FEM). This method is also convenient to calculate the parameters and performance of electrical machines [4]. The LSRM construction is very simple. Both stator and mover have salient poles and only the stator carries winding coils, which are suitably connected to create phases. The magnetic flux is provided by phase current to develop a reluctance force [1]. This machine can operate as a motor or a generator. The three phase basic structure of LSRM is shown in Fig. 1.

This paper is written in cooperation between the University of Žilina and the China university of Mining and Technology in Xuzhou, China, where the LSRM was developed and manufactured. This LSRM is optimized from the point of view of power density, volume and electromagnetic force maximal value. In Fig. 2 there is shown a real prototype of the LSRM where the moving and static parts are separated for illustration. The LSRM from Fig. 2 is analyzed by means of FEM, especially with the FEMM 4.2 software using planar 2D system to calculate static parameters of the real and optimized LSRM, mainly phase inductance, electromagnetic force and flux linkage, needed for a deeper analysis of its performances during dynamic simulation and analysis. The static parameters mentioned above were calculated for different phase current and mover position.
On the base of this analysis, some construction optimizations are carried out. It means that the air gap $\delta$ and mover pole height $h_{m}$ are changed (see Fig. 1). The air gap length in the real LSRM is $2 \mathrm{~mm}$ and it is changed from this value to $0.5 \mathrm{~mm}$ with the step $0.5 \mathrm{~mm}$. The mover pole height $\mathrm{hm}$ is changed from $39 \mathrm{~mm}$ (real LSRM) to $20 \mathrm{~mm}$.

The calculated static parameters of the real and optimized LSRM are input values of LSRM mathematical model to simulate dynamic performances and parameters for constant or various speeds.

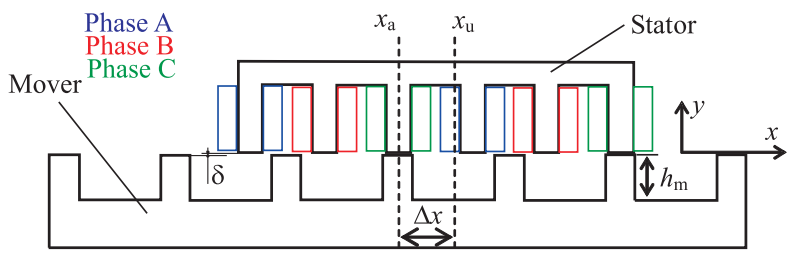

Fig. 1 The three phase LSRM

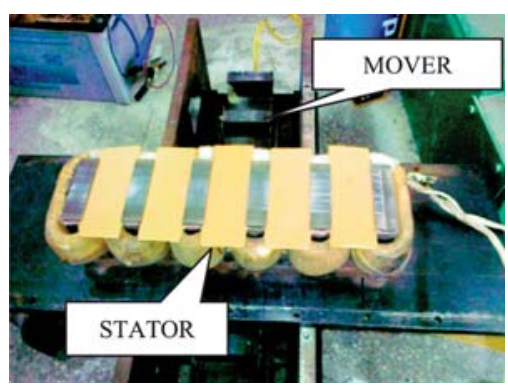

Fig. 2 The three phase LSRM prototype with separated stator and mover

\footnotetext{
* Pavol Rafajdus, Peter Sekerak, Lukas Kalamen, Valeria Hrabovcova ${ }^{1}$, Hao Chen $^{2}$

${ }^{1}$ Department of Power Electrical Systems, Faculty of Electrical Engineering, University of Zilina, Slovakia, E-mail: pavol.rafajdus@kves.uniza.sk

${ }^{2}$ School of Information and Electrical Engineering, China University of Mining and Technology, Xuzhou, China
} 


\section{Static parameters analysis of the LSRM}

For the FEM magnetostatic analysis the following input data are necessary: geometrical dimensions of the machine, current density of one phase, material constants (winding conductivity and relative permeability, B-H curve of LSRM ferromagnetic circuit material) and boundary conditions. The parametric model of LSRM was created in LUA script in the FEMM 4.2 software for more convenient calculation with lower time consumption. The LUA script also enables the LSRM model optimization (changes of the geometry of the machine) during the execution of the script.

The accuracy of the result depends on the size of FEM mesh and accuracy of the input parameters. In our model, 17.000 nodes were used. The calculation was carried out for each individual mover position and current under static condition. The mover position $x$ was moved from aligned $x_{a}$ to unaligned position xu with step of $0.5 \mathrm{~mm}$ and in each position the current was changed within its working range from 1 to 35A. In Fig. 3a the distribution of magnetic flux lines of LSRM for aligned position can be seen, in Fig. 3b for unaligned mover position. The phase current was kept constant $10 \mathrm{~A}$.

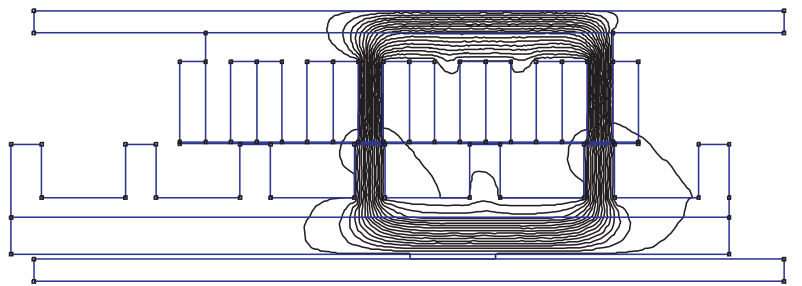

a)

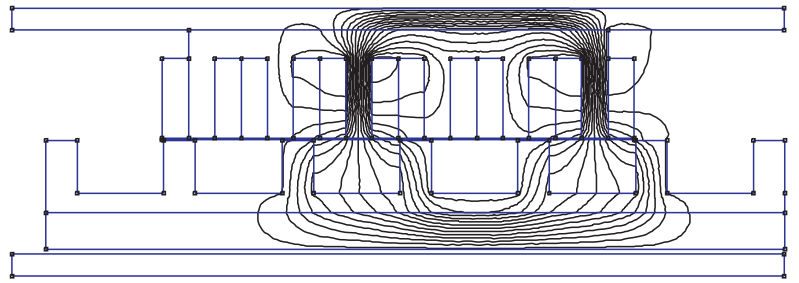

b)

Fig. 3 The distribution of magnetic flux in the real LSRM for phase current $10 \mathrm{~A}$,

a) aligned mover position, b) unaligned mover position

\subsection{Phase inductance calculation}

The phase inductance $L=f(I, x)$ versus mover position for full current range is a static parameter which is needed in the LSRM mathematical model for dynamic simulations. The analysis was made for the whole working range of the real LSRM. The phase inductance profiles are shown in Fig. 4. The origin of the position axis is set to aligned position and the inductance decreases its value for each phase current until the mover and stator are not in unaligned position (Fig. $4 \mathrm{~b}$ ). The results are obtained by means of FEM for the LSRM in accordance with the following equation:

$$
L=\frac{\int A \cdot J d V}{I^{2}},
$$

where $A$ is magnetic vector potential, $J$ is current density, $V$ is volume and $I$ is the phase current.

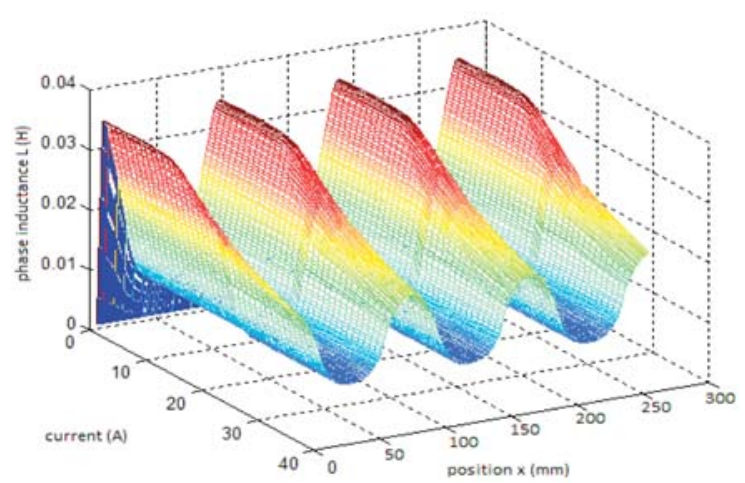

a)

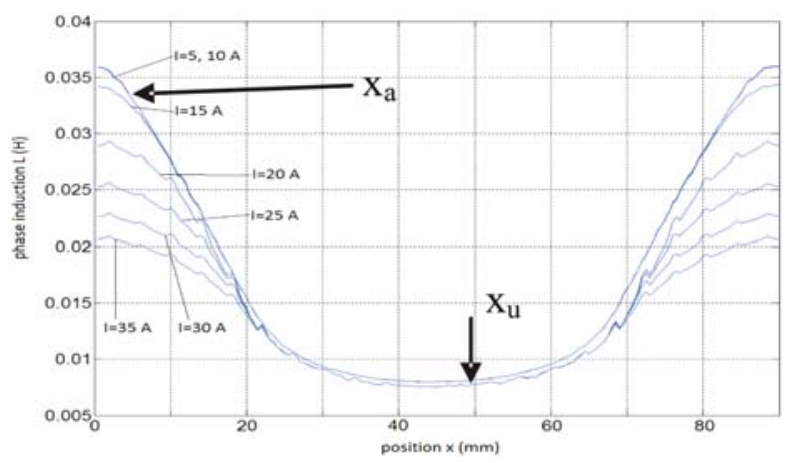

b)

Fig. 4 The phase inductance for different phase currents and mover positions of the real LSRM: a) 3D view, b) $2 D$ view

\subsection{Electromagnetic force calculation}

The electromagnetic force was also calculated by means of FEM. The static force characteristics were obtained for the whole working range. Maxwell's stress tensor prescribes the force per unit area produced by the magnetic field on a surface. The differential force produced at line 1 between mover and stator is:

$$
F=l_{F e} \frac{\mu_{0}}{2} \oint_{l}\left(H_{n}^{2}-H_{t}^{2}\right) d l,
$$

where $n$ denotes the direction normal to the surface at the point of interest, $B$ is flux density and $H$ is intensity of magnetic field. 
The calculated values of electromagnetic force in $x$ direction are shown in Fig. 5a. For more complex analysis the average force $F_{a v}$ is necessary to be known. So the average force is given as:

$$
F_{a v}=\frac{1}{\Delta x} \int_{x_{a}}^{x_{u}} F d x .
$$

where $\Delta x$ is defined as $\Delta x=x_{a}-x_{u}$ and it is the difference between aligned mover position $x_{a}$ and unaligned mover position $x_{u}$. In this case the difference is $45 \mathrm{~mm}$. The phase current was kept constant $I=5,10,15,20,25,30,35$ and average electromagnetic force for LSRM is shown in Fig. 5b, calculated for interval $\Delta x$.

\subsection{Optimization of the LSRM construction}

As it has been mentioned above, optimization of the LSRM construction was carried out. In the first step, the air gap $\delta$ was

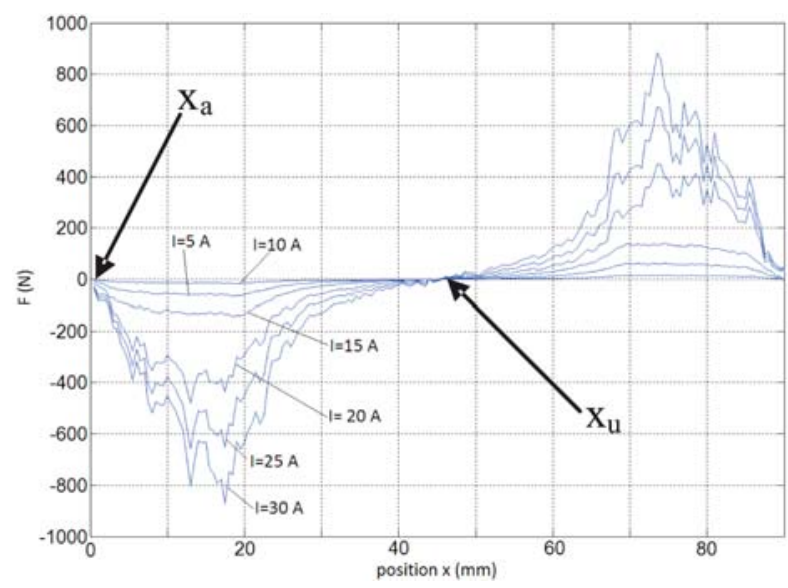

a) changed between stator and mover (see Fig.1) from real size $2 \mathrm{~mm}$ to $0.5 \mathrm{~mm}$. The phase current was kept constant $I=25 \mathrm{~A}$, which is the rated value. The static parameters were calculated by means of FEM, mainly phase inductance and electromagnetic force in the air gap, which are needed for the dynamic mathematical model. These static parameters can be seen in Fig.6.

In the second step, the mover pole height hm (see Fig.1) was changed from its real size of $39 \mathrm{~mm}$ up to $20 \mathrm{~mm}$. The phase current was kept constant $I=25 \mathrm{~A}$ and air gap was also constant $0.5 \mathrm{~mm}$. The phase inductance and electromagnetic force were also calculated by means of FEM. These static parameters can be seen in Fig. 7.

For comparison, in Fig. 8 are shown behaviors of average electromagnetic force values Fav for both of optimizations: different air gap lengths (see Fig. 8a) and different mover pole heights (see

Fig. 5 The LSRM electromagnetic force of the real LSRM: a) static curves, b) average forces

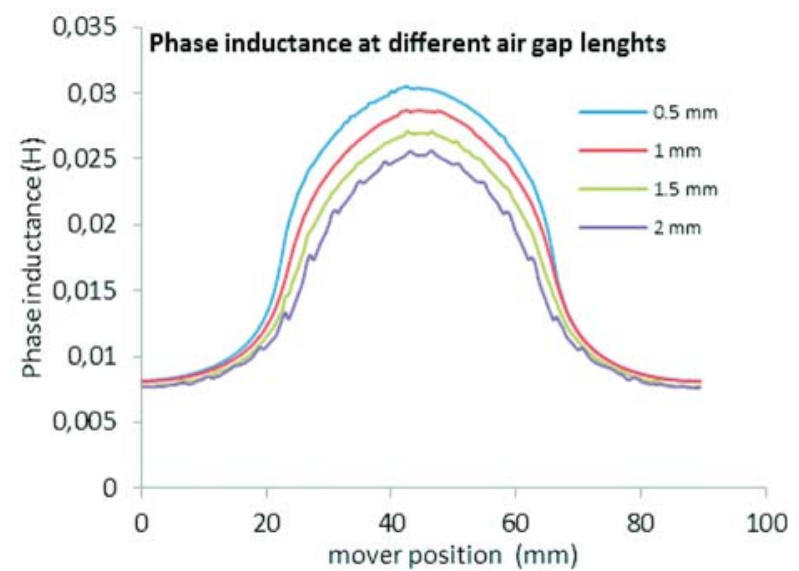

a)

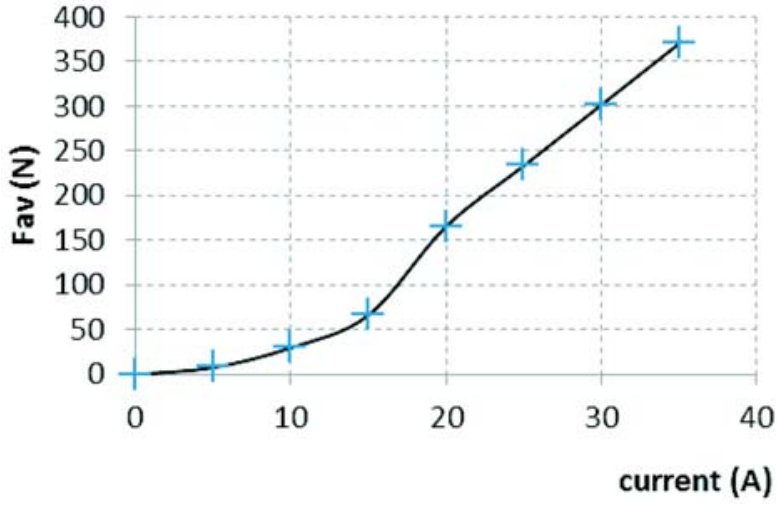

b)

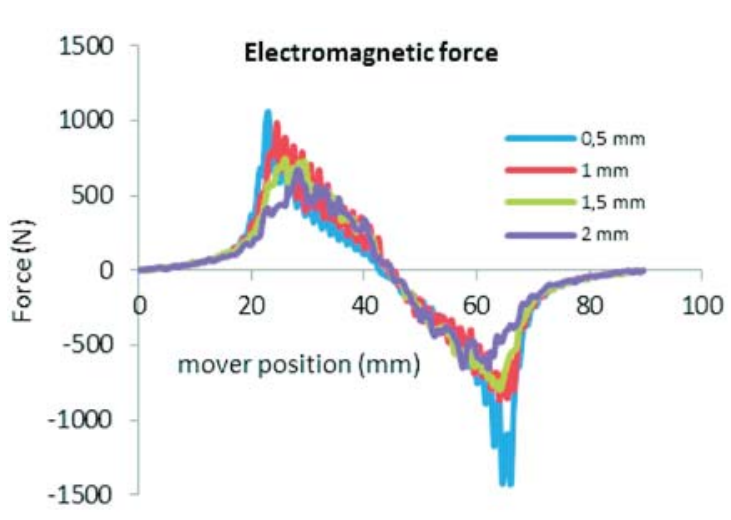

b)

Fig. 6 The LSRM static parameters obtained by means of FEM for various air gap lengths, a) phase inductance, b) electromagnetic force 


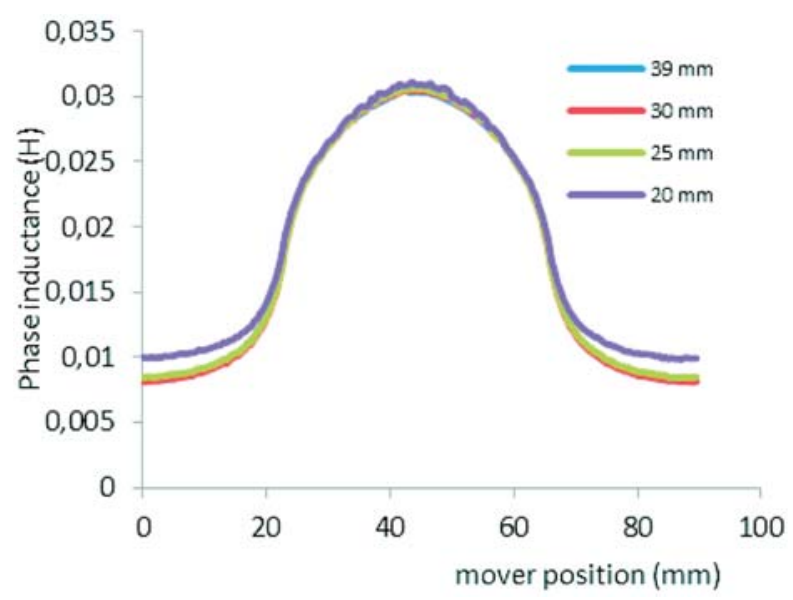

a)

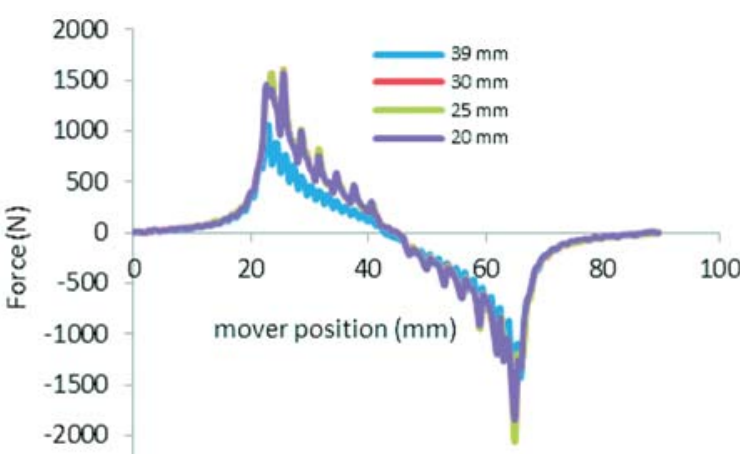

b)

Fig. 7 The LSRM static parameters obtained by means of FEM for various mover pole heights, a) phase inductance, b) electromagnetic force

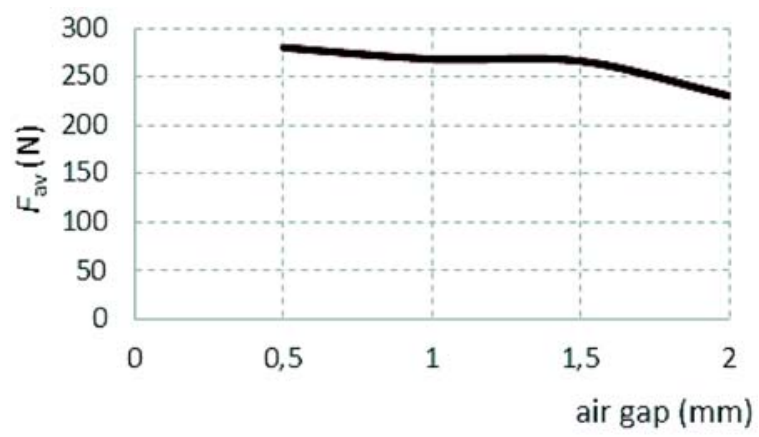

a)

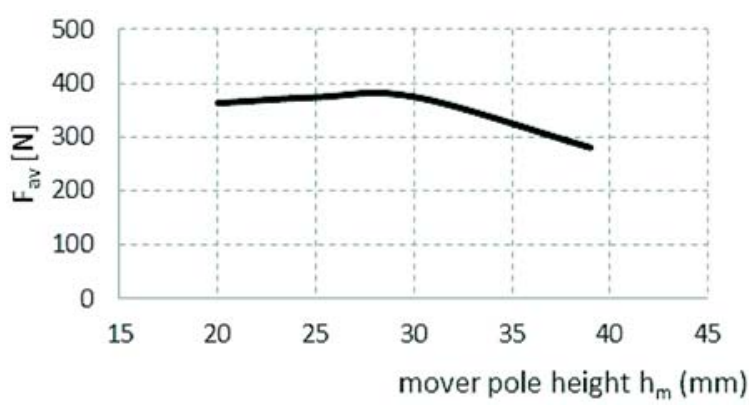

b)

Fig. 8. The LSRM average electromagnetic force, a) for various air gap lengths, b) for various mover pole heights

Fig. 8b). As it can be seen from these figures, the maximal average electromagnetic force $375 \mathrm{~N}$ occurs for air gap $0.5 \mathrm{~mm}$ and mover pole height $28 \mathrm{~mm}$. In opposite, the lowest value of average electromagnetic force $235 \mathrm{~N}$ is for the real LSRM (see Fig. 2).

\section{Dynamic Analysis of the LSRM}

For the dynamic analysis, the nonlinear mathematical model was used [8]. The phase current was calculated from the next equation:

$$
\frac{d i}{d t}=\frac{u-\left(R+\frac{d L(x, i)}{d x} \frac{d x}{d t}\right) i}{L(x, i)}=\frac{u-\left(R+\frac{d L(x, i)}{d x} v\right) i}{L(x, i)}
$$

where the input voltage $u$ was changed in accordance with the current regulator, $R$ is the phase resistance obtained from measurement, $L$ is phase inductance obtained from FEM and $v$ is speed of the mover. The instantaneous force of one phase $f$ was calculated from the 2D look up table by means of linear interpolation, because it is faster than to calculate it from equation. The values of 2D force table were obtained from FEM. The total instantaneous force of all phases is calculated as:

$$
f=\sum_{j=1}^{m} f_{j}(x, i)
$$

The real speed of the mover can be calculated from the equation:

$$
\frac{d v}{d t}=\frac{1}{J}\left(\sum_{j=1}^{m} f_{j}(x, i)-f_{\text {load }}\right)
$$

where $J$ is the moment of inertia and fload is load force. Finally, the mover position is given as:

$$
x=\int v d t
$$

This mathematical model was simulated under Matlab/Simulink. The input parameters as phase inductance and force were taken from the static analysis for real LSRM and optimized LSRM (air gap $0.5 \mathrm{~mm}$ and mover pole height $28 \mathrm{~mm}$ ). In accordance with the equation (7), the mover speed v started from $0 \mathrm{~m} / \mathrm{s}$ to $1.5 \mathrm{~m} / \mathrm{s}$. From 


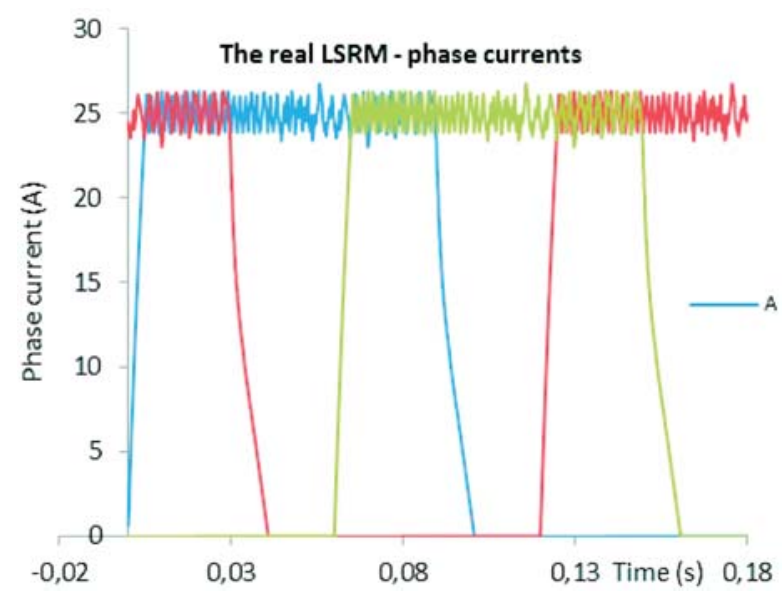

a)

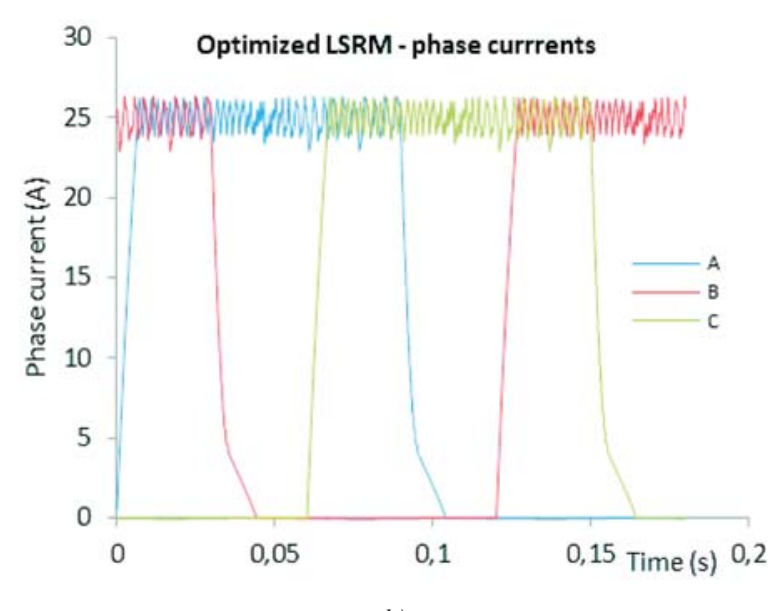

b)

Fig. 9 The LSRM phase current waveforms, a) real, b) optimized

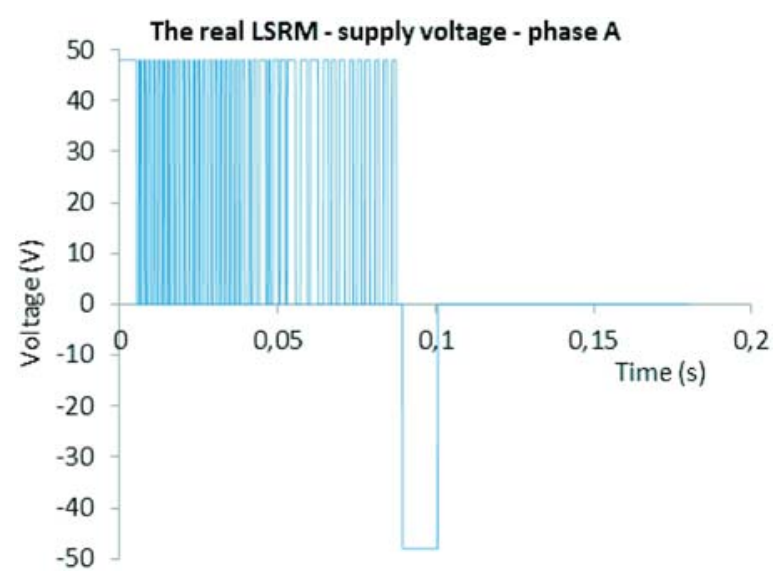

a)

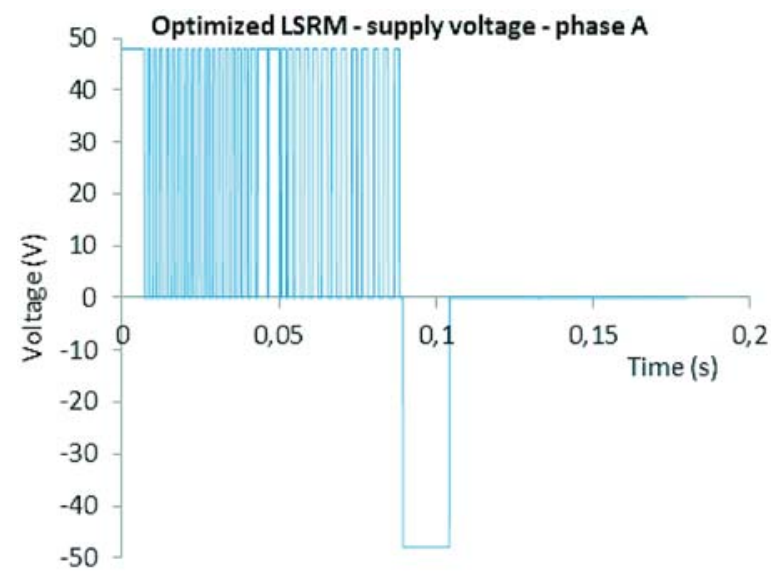

b)

Fig. 10 The LSRM phase voltage waveforms, a) real, b) optimized

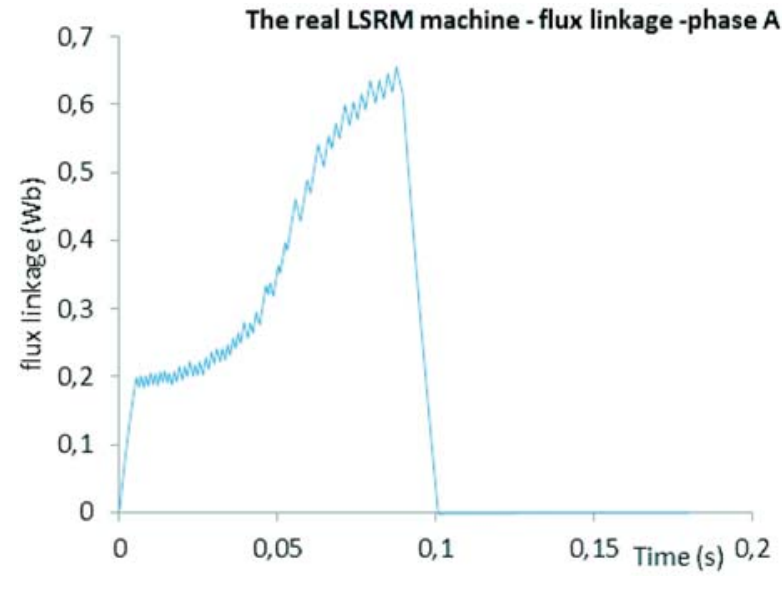

a)

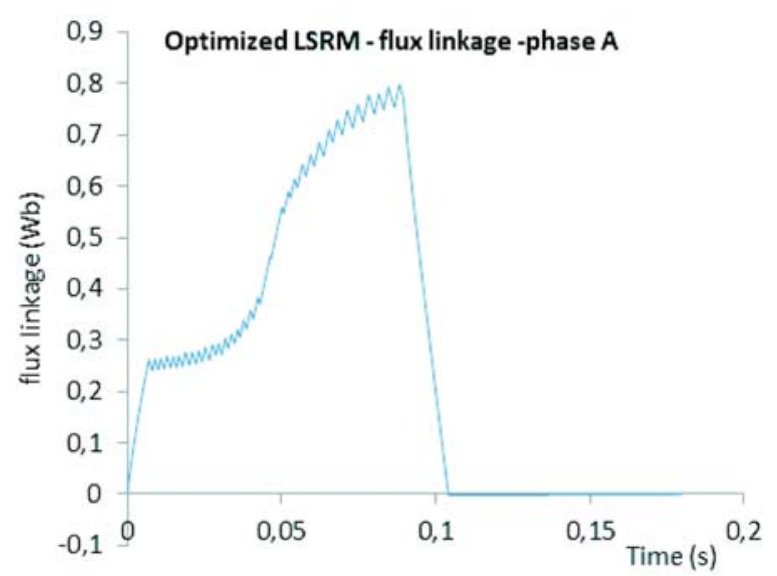

b)

Fig. 11 The LSRM flux linkage waveforms, a) real, b) optimized

10 COMMUNICATIONS 4/2011 

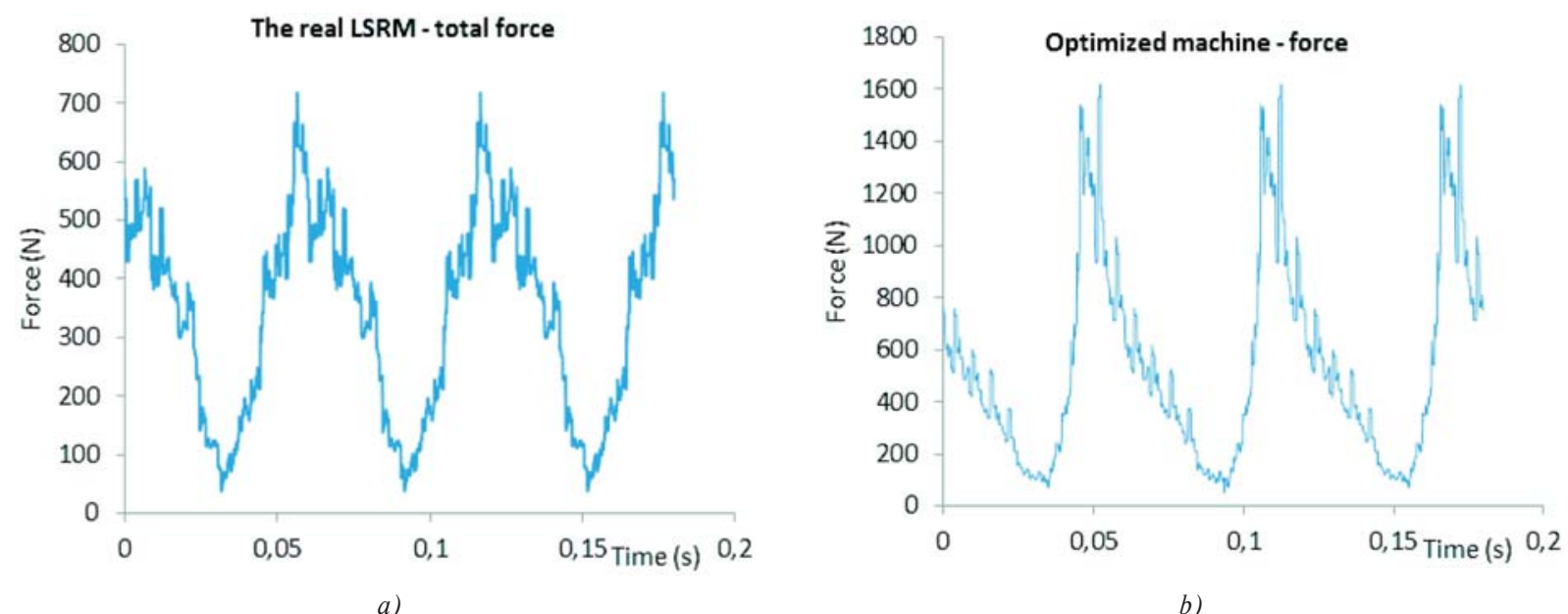

Fig. 12 The LSRM total electromagnetic force waveforms, a) real, b) optimized

this mathematical model and simulation system next waveforms were calculated: phase currents, phase voltage, flux linkage and instantaneous force. These waveforms were calculated for different speeds from $0 \mathrm{~m} / \mathrm{s}$ to $1.5 \mathrm{~m} / \mathrm{s}$. The phase current was kept on reference current $25 \mathrm{~A}$ by the current regulator. The phase current waveforms, phase voltage waveforms, flux linkage and total force of the real and optimized LSRM can be seen in Figs. 9, 10, 11 and 12 respectively.

As it can be seen from Fig.12, the maximal value of optimized LSRM total force is higher than in the real original LSRM. In opposite, the force ripple of optimized LSRM is higher than in the real LSRM, which can be decreased by a next construction or control LSRM optimization.

\section{Conclusion}

The static parameters of the real and optimized LSRM were investigated by means of FEM. The phase inductance and force of the machine were calculated for each mover position and phase current. The average force was calculated and compared with the LSRM optimized construction. The mathematical model was described and solved to obtain dynamic waveforms of phase currents, voltages, flux linkage and total force. The investigated parameters will be compared with measurement ones in a future work. It is obvious that there are still some imperfections in the machine design and hence our future effort will be set on the efficiency improvement of the LSRM.

\section{Acknowledgement}

This work was supported by the Slovak Research and Development Agency under the Contract No. SK-CN-0020-09 and by VEGA (Scientific Grant Agency of the Slovak Republic) No. $1 / 0809 / 10$.

\section{References}

[1] MILLER, T. J. E.: Switched Reluctance Motors and their Control. Magna Physics Publishing, Oxford 1993

[2] BYEONG-SEOK LEE; HAN-KYUNG BAE; VIJAYRAGHAVAN, P.; KRISHNAN, R.: Design of a Linear Switched Reluctance Machine, Industry Applications, IEEE Transactions on Vol. 36, 2000, pp: 1571-1580

[3] CHEN, H.; WANG, X.; GU, J.J.; LU, S.: Design of Bilateral Switched Reluctance Linear Generator, Electric Power and Energy Conference (EPEC), 2010 IEEE, 2010 , pp. 1-5

[4] KRISHNAN, R.: Switched Reluctance Motor Drives - Modelling, Simulation, Analysis, Design, and Applications, CRC Press LLC, FLA, USA, 2000.

[5] CHEN, H.; ZHANG. CH.; ZHAO, X.: Research on the Switched Reluctance Wind Generator System, IEEE International Conference on Systems, Man, and Cybernetics, Tucson, 2001.

[6] RAFAJDUS, P., HRABOVCOVA, V., HUDAK, P.: Investigation of Losses and Efficiency in Switched Reluctance Motor, $12^{\text {th }}$ International Power Electronics and Motion Control Conference, EPE-PEMC 2006, Portorož, Slovenia, 2006, 08, pp.: T4-309

[7] PYRHONEN, J.; JOKINEN, T.; HRABOVCOVA, V.: Design of rotating electrical machines, John Wiley \& Sons, 2008,

[8] HRABOVCOVA, V.; RAFAJDUS, P.; LICKO, M.; JANOUSEK, L.: Modelling of the Dynamic Operation of the Switched Reluctance Drive by Simulink, SPEEDAM'98, Sorrento, 1998, p. P1-61 - P1-66. 